\title{
I \\ OS ESTÁGIOS NAS LICENCIATURAS DA UFTM E SUA RELAÇÃO COM OS MUSEUS DE UBERABA/MG*
}

\author{
Carolina Kiyoko Mellini \\ Aline Resende Gomes
}

\section{Introdução}

Os espaços não formais de educação podem ser entendidos como locais em que há possibilidade de ocorrer uma prática educativa. Duas categorias podem ser interpretadas para caracterizar esses espaços: Espaços Institucionalizados e Espaços Não-Institucionalizados (JACOBUCCI, 2008). Os Espaços Institucionalizados incluem os locais que são regulamentados e que possuem uma equipe técnica responsável pelo desenvolvimento de atividades, a exemplo de Centros de Ciências, Museus, Parques Zoobotânicos, Parques Zoológicos, Planetários e Jardins Botânicos, entre outros. Por outro lado, a categoria que abrange os Espaços Não-Institucionalizados inclui os ambientes naturais ou urbanos que não apresentam uma estruturação institucional, mas nos quais existe a possibilidade de adotar diferentes práticas educativas, como teatros, parques, casas, praças, cinemas, cavernas, praias e campos de futebol. No que se refere ao desenvolvimento deste trabalho, abordaremos um tipo de espaço institucionalizado: os Museus.

Os museus apresentam grandes contribuições para a formação docente no âmbito não formal, mas nem sempre são contemplados nas matrizes curriculares (de modo obrigatório) dos cursos que formam professores. Os espaços museológicos buscam responder ao que podemos chamar de uma nova responsabilidade social, por meio de uma crescente profissionalização dos serviços oferecidos aos seus dife-

*DOI - 10.29388/978-65-86678-24-6-0-f.17-38 
rentes públicos, inclusive aos professores em formação (BRANDÃO; LANDIM, 2011).

A demanda por melhorias na formação inicial do professor sempre existiu, acrescentando, por exemplo, novas estratégias de ensino (como a visita aos museus), na expectativa de que diretamente ou indiretamente a escola ampliasse suas possibilidades educacionais e melhorasse a sua qualidade (PUGLIESE, 2015). As visitas aos museus podem contribuir para a formação de professores, tanto inicial quanto continuada, possibilitando diferentes experiências (afetivas, envolventes e motivadoras) (GAREAU; GUO, 2012). Entretanto, para que essas experiências sejam de fato produtivas, segundo Gareau e Guo (2012), é necessário seguir determinados passos: por parte dos museus, as exposições devem ser atrativas e interativas, precisam ter sido pensadas por professores e educadores de museus e, para a escola, é necessário que haja planejamento prévio à visita (considerando a elaboração de atividades pré-visita e pós-visita).

Pensando nestes aspectos, norteamos nossas discussões a partir de três caminhos interligados: "Espaços não formais: os museus de Uberaba", "Estágio Curricular Supervisionado nos cursos de Licenciaturas da UFTM" e "O museu e a formação inicial de professores". O primeiro engloba conceituações sobre os museus, bem como a apresentação dos museus localizados no município de Uberaba, Minas Gerais. Em seguida, buscamos identificar possíveis relações entre os cursos de licenciatura na Universidade Federal do Triângulo Mineiro (UFTM) e o desenvolvimento de estágio curricular supervisionado. Por fim, dissertamos sobre as potencialidades de se estudar, visitar, conhecer e divulgar os museus (enquanto espaços não formais de educação), com foco nos estágios dos cursos de formação docente.

Assim, este texto tem como objetivo refletir se os estágios da UFTM, por meio de suas diretrizes curriculares, permitem ou não a aproximação com a educação não formal, principalmente com os museus definidos pela Fundação Cultural de Uberaba, a saber: Museu de Arte Decorativa - MADA, Museu do Zebu - Fundação Edilson La- 
martine Mendes, Museu de Arte Sacra - MAS, Casa de Memorias e Lembranças Chico Xavier, Memorial Chico Xavier, Museu dos Dinossauros - MD e Museu Memória Viva e Museu da Capela - Irmãs Dominicanas de Monteils.

\section{Espaços não formais: os museus de Uberaba}

Os espaços não formais, segundo Marandino (2008), incluem locais que oferecem qualquer atividade organizada fora do sistema formal de educação, como centros culturais, jardins botânicos, zoológicos e museus. Estes espaços podem funcionar separadamente ou como parte de uma atividade mais ampla, que pretende atender aos públicos previamente identificados como aprendizes, e que possui objetivos de aprendizagem.

Nessa perspectiva, Hofstein e Rosenfeld (1996) deixam explícito que apesar das características próprias de cada contexto educacional, a educação não formal pode ser entendida como um complemento importante à educação formal. Os autores entendem que a educação formal e a não formal devem ser vistas como um continuum de contextos de aprendizagem. Diante destes pressupostos, este texto discute questões voltadas à importância da educação não formal, destacando o museu como um espaço privilegiado deste contexto, e também investigar possíveis relações existentes entre os estágios supervisionados dos cursos de licenciatura da UFTM e os espaços não formais de educação, em particular os museus de Uberaba descritos pela Fundação Cultural do município.

Queiroz e colaboradores (2002) destacam a importância do espaço não formal, especificamente os museus, para a educação em ciências e tecnologia, de modo que seja indispensável acrescentar a exploração educativa do seu conjunto material e simbólico, devido às atribuições de preservação e estudos de seus acervos. Segundo o Instituto 
Brasileiro de Museus (IBRAM ${ }^{1}$ ) e a Lei no 11.904 , de 14 de janeiro de 2009, museus podem ser entendidos como:

[...] instituições sem fins lucrativos que conservam, investigam, comunicam, interpretam e expõem, para fins de preservação, estudo, pesquisa, educação, contemplação e turismo, conjuntos e coleções de valor histórico, artístico, científico, técnico ou de qualquer outra natureza cultural, abertas ao público, a serviço da sociedade e de seu desenvolvimento (BRASIL, 2009, online).

Essa definição vai ao encontro da conceituação de museus pelo Conselho Internacional de Museus $\left(\mathrm{ICOM}^{2}\right)$, órgão internacional que caracteriza esses espaços como uma instituição permanente, sem fins lucrativos, a serviço da sociedade e do seu desenvolvimento, aberta ao público e que adquire, conserva, investiga, difunde e expõe os testemunhos materiais do homem e de seu entorno, para educação e deleite da sociedade.

Destarte, podemos considerar o museu como espaço privilegiado dentro da educação não formal, o qual vem desenvolvendo sua função educativa e, assim, contribuindo com o transpor dos muros da escola (CAZELLI, 2010) na direção de uma educação mais integral e de natureza social. Um estudo realizado por Lavoie (1991) revela que os grupos escolares representam $70 \%$ das pessoas que visitam os museus. Neste contexto, estes espaços têm se desenvolvido, especialmente em sua pedagogia - nos aspectos de tempo, objeto e espaço - para elaborar modelos próprios de ensino para os seus visitantes. Entretanto, nota-se ainda uma carência de base teórica, de modo que os educadores dos museus, na maioria das vezes, não conseguem divulgar o co-

\footnotetext{
${ }^{1}$ O IBRAM foi criado em 2009 a partir da Lei no 11.906 , sendo que a nova autarquia vinculada ao Ministério da Cultura (MinC) sucedeu ao Instituto do Patrimônio Histórico e Artístico Nacional (Iphan) nos direitos, deveres e obrigações relacionados aos museus federais. Disponível em: http://www.museus.gov.br/acessoainformacao/o-ibram/ Acesso em: 18 fev. 2019.

${ }^{2}$ ICOM - International Council of Museums - (Conselho Internacional de Museus) é uma organização internacional não-governamental de museus e de profissionais de museus, fundada em 1947 para levar em frente os interesses da Museologia e outras disciplinas relacionadas com gerência e operações de museus.
} 
nhecimento de forma efetiva, podendo ocasionar lacunas na componente de formação cultural dos alunos que visitam estas instituições.

Por outro lado, vale ressaltar a importância dos profissionais que atuam na mediação entre o museu e os seus visitantes, pois é por meio destes que, na maioria das vezes, uma visita se torna significativa para o visitante. Todavia, Allard e colaboradores (1995) chamam atenção para uma problemática: o fato de as visitas aos museus não serem relacionadas ao currículo escolar, de modo que os professores e gestores, ao sugerirem esse tipo de atividade, se deparam com dificuldades burocráticas, como transporte, alimentação e utilização de aulas de outros professores para a operacionalização da visita, entre outras. Partindo desse pressuposto, os autores defendem a proposta educativa ao museu em uma interlocução com a escola, ou seja, que as atividades de visitantes escolares a estes espaços sejam precedidas por atividades preparatórias na escola e, posteriormente, pela visita. Os autores complementam, ainda, que as atividades que os alunos realizam após uma visita a um museu são significativas tanto quanto as que são realizadas antes ou durante a visitação.

Deste modo, entende-se a importância dos museus como espaços de formação não restritos aos alunos, mas abrangendo professores e profissionais das mais diferentes áreas, bem como toda a sociedade. Embora a integração do museu com a escola represente um desafio para professores e gestores, os efeitos de uma visita ao museu articulada por atividades de preparação e de extensão em sala de aula podem ressignificar o ensino, sendo alicerces para reflexão e preparação de novos caminhos didáticos, de modo a maximizar currículos e propiciar a aproximação entre museus e escolas em uma ação conjunta na busca por melhorias nos processos de ensino e aprendizagem.

Frente ao panorama apresentado, à conceituação dos espaços não formais de educação e dos museus, apresentaremos de forma mais detalhada os museus localizados na cidade de Uberaba/MG, elencados por sua Fundação Cultural e Prefeitura Municipal. A cidade de Uberaba, localizada no Estado de Minas Gerais e pertencente à região conhe- 
cida como Triângulo Mineiro, é particularmente rica em espaços museológicos. Em acordo com as fontes indicadas, existem oito museus em atividade na cidade: Museu de Arte Decorativa - MADA, Museu do Zebu - Fundação Edilson Lamartine Mendes, Museu de Arte Sacra - MAS, Casa de Memorias e Lembranças Chico Xavier, Memorial Chico Xavier, Museu dos Dinossauros - MD e Museu Memória Viva e Museu da Capela - Irmãs Dominicanas de Monteils.

O Museu de Arte Decorativa (MADA) localiza-se em um espaço que no passado foi fazenda, constituída no ano de 1916 (Figura 1). Seu acervo conta com uma biblioteca composta por exemplares de livros de diferentes áreas do conhecimento, móveis de época e porcelanas inglesas da década de 1920. O espaço tem uma área de exposição das obras do artista uberabense Reis Júnior, pinturas em tela que retratam a família. "O museu também promove exposições temporárias de arte e de música mostrando diversos aspectos da cultura brasileira" (UBERABA, 2019, online).

Figura 1. Museu de Arte Decorativa (MADA)

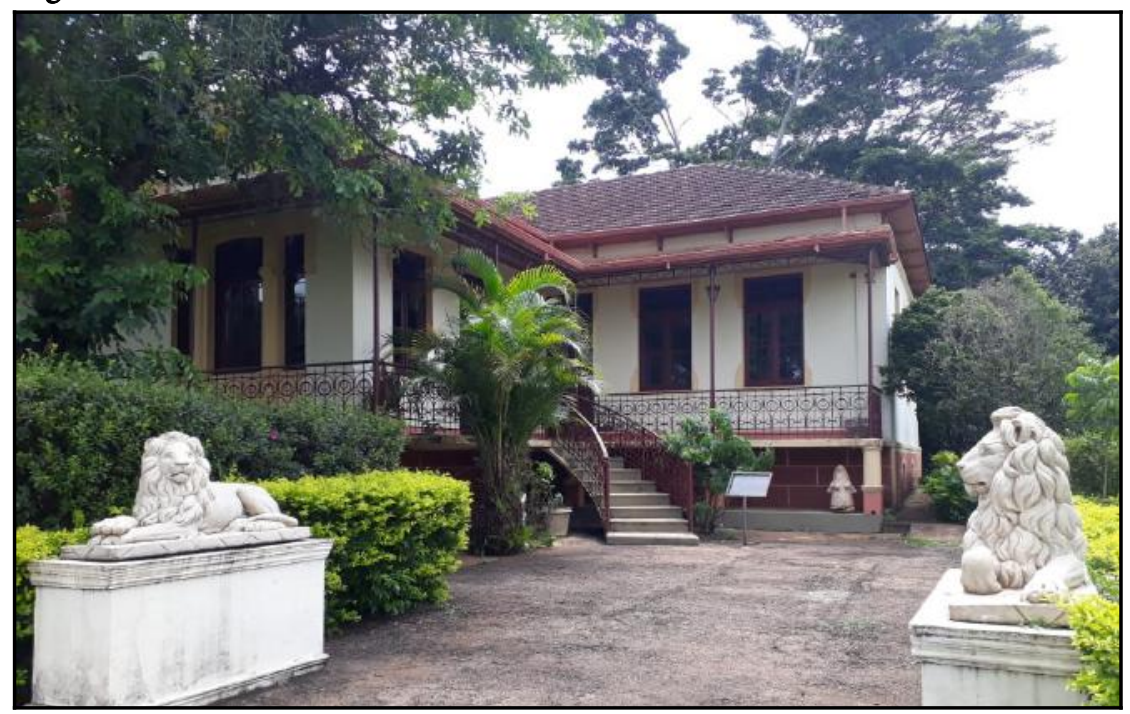

Fonte: autoras (2019) 
O Museu do Zebu - Fundação Edilson Lamartine Mendes (Figura 2) foi aberto ao público durante a 50a Expozebu, no dia 2 de maio de 1984 (ABCZ, 2019, online). Nos seus primeiros anos de existência, o museu era apenas um departamento da Associação Brasileira de Criadores de Zebu (ABCZ). Durante a década de 1990, a instituição passou a ser uma Fundação na busca pela ampliação da sua atuação e compromisso socioeducacional. Está localizado no Parque Fernando Costa e seu acervo conta a saga do gado Zebu no Brasil e no mundo, a partir do fim do século XIX. Único do gênero no mundo, seu acervo é constituído por peças, fotos, livros e documentos. O museu conta com exposição permanente e mostras anuais temporárias, sempre relacionadas à zebuinocultura (UBERABA, 2019, online).

Figura 2. Museu do Zebu

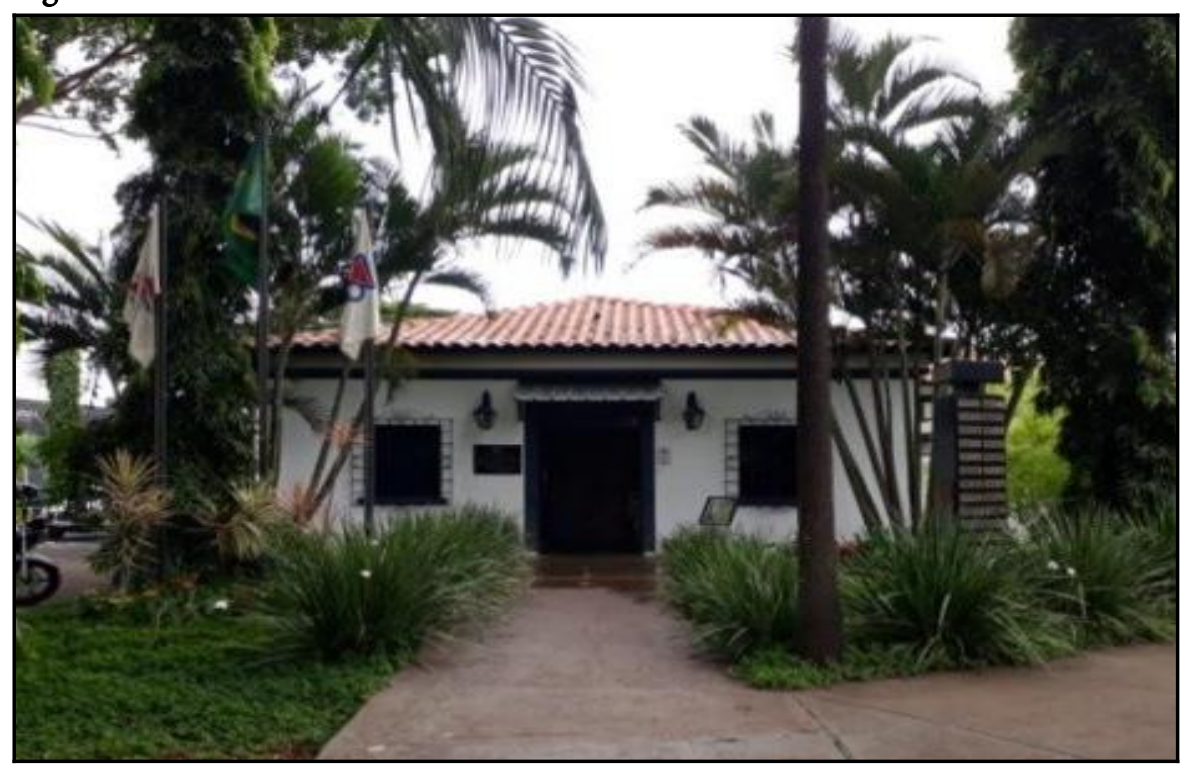

Fonte: autoras (2019)

O Museu de Arte Sacra está “instalado na Igreja Santa Rita, que foi construída no ano de 1854 e foi tombada pelo Patrimônio Histórico e Artístico Nacional em 1939" (UBERABA, 2019, online). O acervo é bastante diversificado e constituído de peças barrocas dos séculos XIX e XX, além de inúmeras vestes litúrgicas doadas pela Cúria $\mathrm{Me-}$ 
tropolitana, estandartes de procissões, tais como: paramentos de sacerdotes, alfaias, imagens de diversos santos da igreja católica e mobiliário de época (UBERABA, 2019, online). Na Figura 3 encontra-se a vista externa do museu.

Figura 3. Museu de Arte Sacra

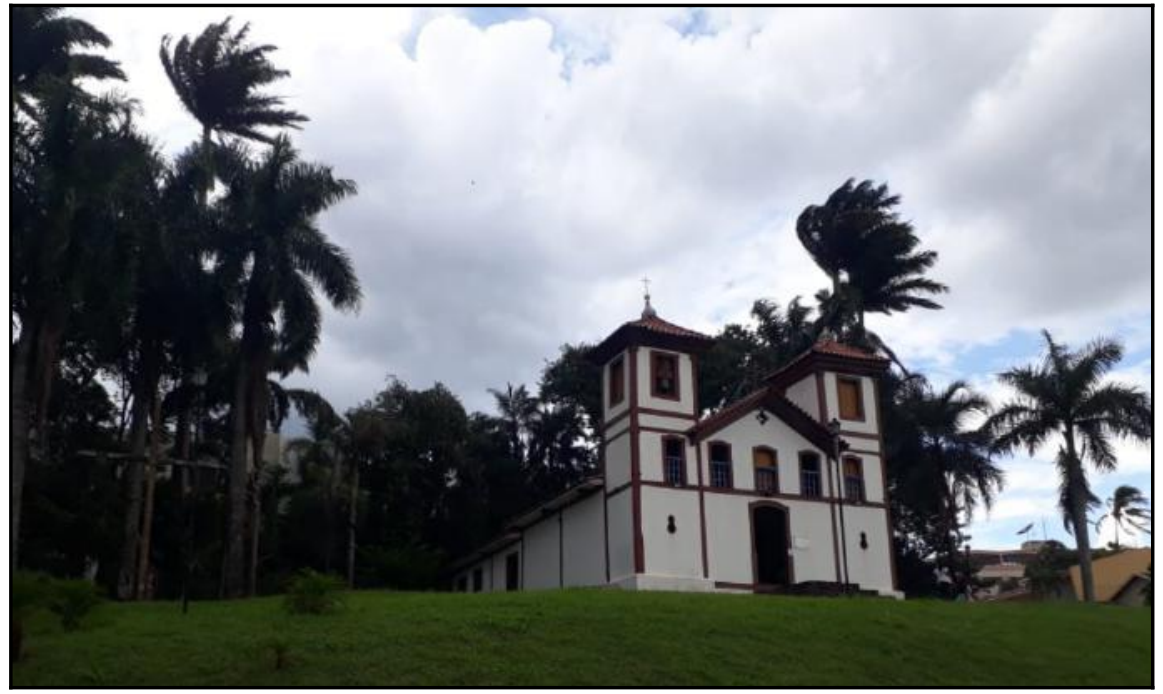

Fonte: autoras (2019)

A Casa de Memórias e Lembranças Chico Xavier (Figura 4) corresponde à residência de Francisco Cândido Xavier, popularmente conhecido por Chico Xavier, médium, psicógrafo e um dos maiores expoentes da doutrina espírita também em âmbito internacional. A casa em que residia no município de Uberaba, Minas Gerais, foi transformada em Museu, tendo em exposição os cômodos da casa com seus pertences pessoais, visando principalmente à preservação de sua memória (UBERABA, 2019, online). 
Figura 4. Casa de Memórias e Lembranças Chico Xavier

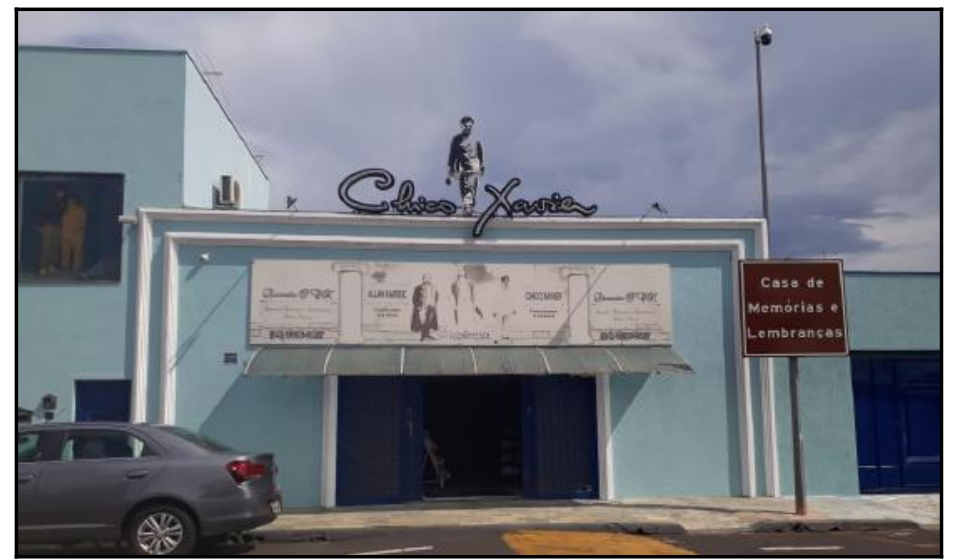

Fonte: autoras (2019)

Um outro espaço dedicado a Chico Xavier no município corresponde ao Memorial Chico Xavier (Figura 5), que está incorporado à Mata do Carrinho, área verde situada no perímetro urbano. Foi criado pela Lei Municipal no 12.448/2016 e compreende um espaço independente da Casa de Memórias e Lembranças Chico Xavier. O prédio conta com espaços multifuncionais, com galerias de exposições, biblioteca, Centro de Pesquisa e Documentação, auditório e praças contemplativas (UBERABA, 2019, online).

Figura 5. Memorial Chico Xavier

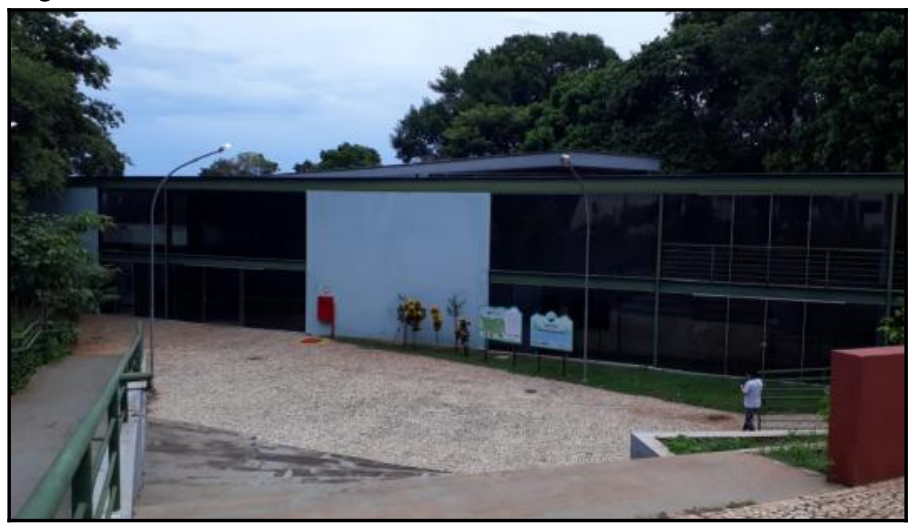

Fonte: autoras (2019) 
O Museu dos Dinossauros (Figura 6) faz parte do Complexo Cultural e Científico de Peirópolis - CCCP, junto ao Centro de Pesquisas Paleontológicas "Llewellyn Ivor Price", sendo vinculado à Universidade Federal do Triângulo Mineiro (UFTM), tendo como tema principal os fósseis e as paisagens da região de Uberaba há cerca de 70 milhões de anos. O museu possui um rico acervo de fósseis de dinossauros e outros vertebrados. Os dinossauros estão presentes em sua maioria na forma de fósseis ou réplicas, como Uberabatitan ribeiroi ( $o$ maior dinossauro do Brasil), Abelissauros (dinossauros carnívoros), Maniraptora (a dino-ave de Peirópolis), Uberabasuchus terrificus e Campinasuchus dinizi (crocodilos), Uberabatrachus carvalhoi (rã), Cambaremys langertoni (tartaruga), Pristiguana brasiliensis (lagarto), entre outros. Conta, ainda, com painéis explicativos sobre a evolução da vida e diagramas que reconstituem de maneira realística os cenários da vida e dos animais e vegetais que habitaram a região de Uberaba há milhões de anos. O museu está instalado no prédio da antiga estação ferroviária de Peirópolis, construída em 1889, em estilo inglês, e conta com um segundo espaço em musealização, na sede do CCCP (UFTM, 2019, online).

Figura 6. Museu dos Dinossauros, (a) Museu dos Dinossauros e (b) sede do CCCP

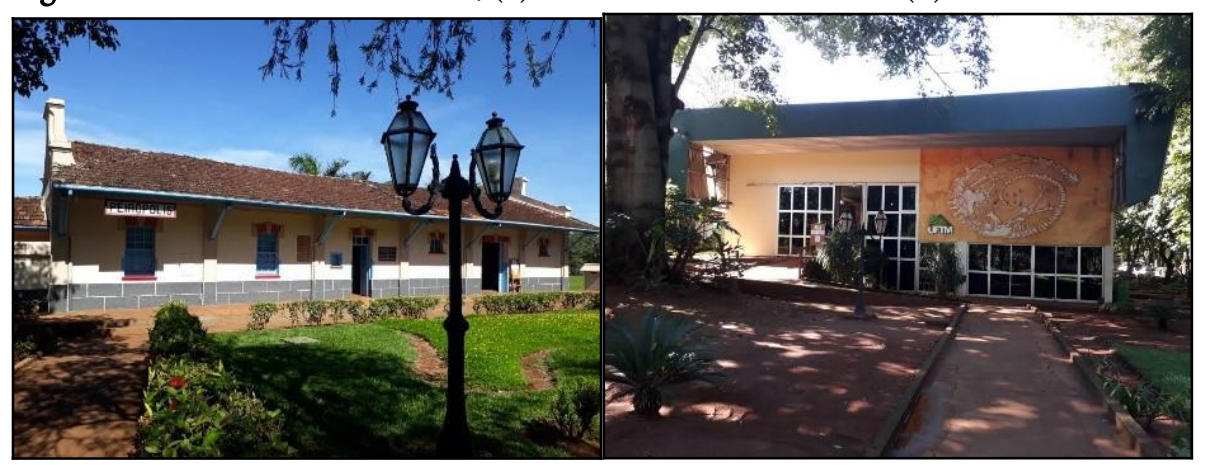

a)

b)

Fonte: autoras (2019)

O Museu Memória Viva (Figura 7) foi criado em 2018 com o objetivo de ser um espaço não formal de educação, arte e cultura na 
Universidade Federal do Triângulo Mineiro (UFTM). O espaço situase nas dependências da UFTM e promove exposições que contemplam os conceitos de evolução e grau de complexidade dos seres vivos. A proposta do museu é propiciar um espaço que promova experiências educativas para que os visitantes compreendam princípios científicos e instigar aproximações com as ciências da vida (UFTM, 2018, online).

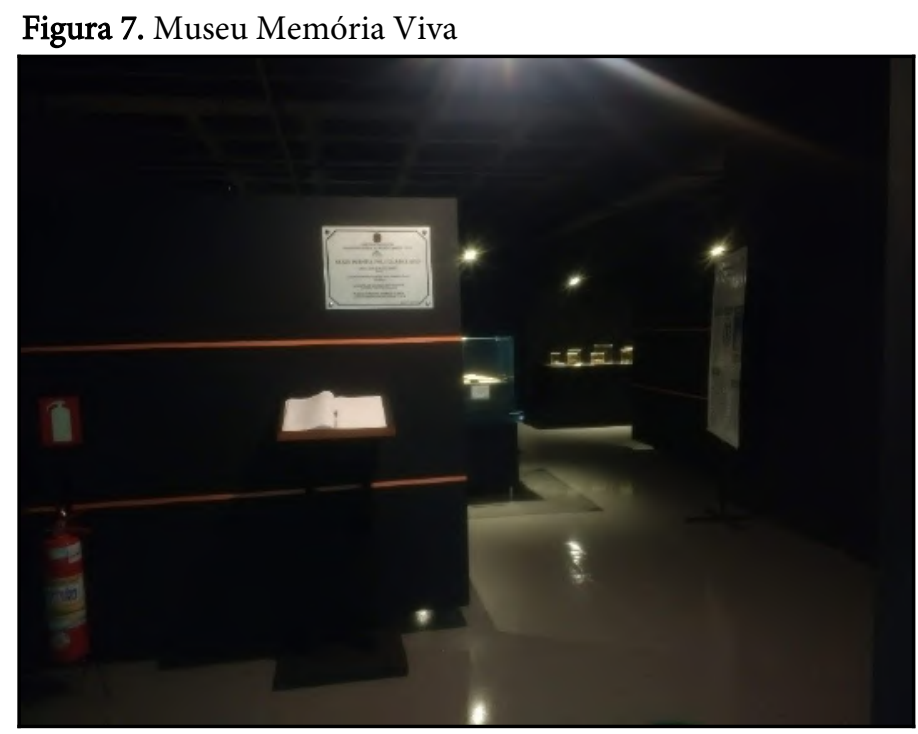

Fonte: autoras (2019)

O último museu elencado pela Fundação Cultural de Uberaba é o Museu da Capela - Irmãs Dominicanas de Monteils (Figura 8), que "reúne objetos e documentos relacionados à história da Congregação das Irmãs Dominicanas de Nossa Senhora do Rosário de Monteils, bem como uma importante coleção de rochas e minerais" (UBERABA, 2019, online). Este museu compreende um espaço de preservação e divulgação da Memória da Congregação, que deu início às suas atividades em 1985, durante as comemorações do Centenário do Colégio Nossa Senhora das Dores. A Congregação possui origem francesa e atua há cerca de 168 anos na Europa, América Latina-Caribe e Ásia; já no Brasil, as Irmãs Dominicanas de Monteils atuam há aproximadamente 133 anos (UBERABA, 2019, online). 
Figura 8: Museu da Capela

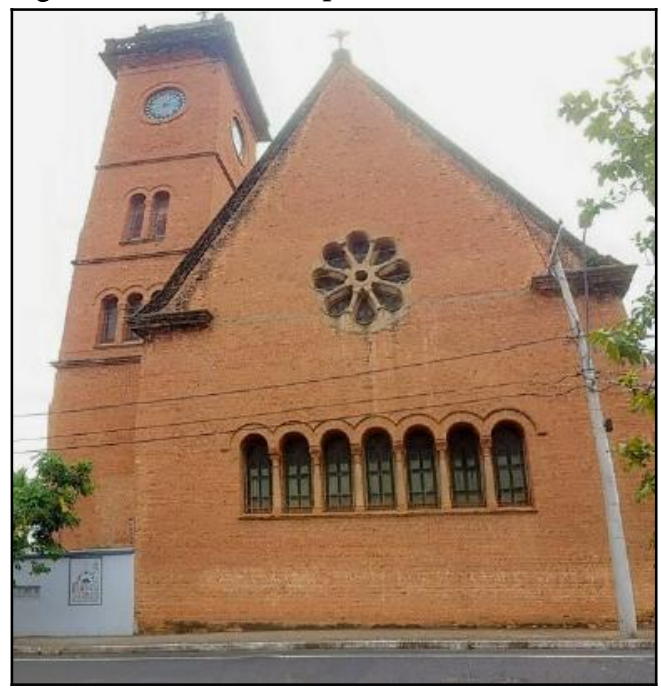

Fonte: autoras (2019)

Dessa forma, frente ao levantamento acerca dos museus existentes em Uberaba, percebemos que o potencial turístico do município é extremamente vasto, abrangendo o artesanato, a paleontologia, o conhecimento do corpo humano e o patrimônio histórico-cultural. A seguir, apresentaremos os estágios curriculares supervisionados oferecidos às licenciaturas da UFTM, de modo a investigar se os respectivos cursos se preocupam em evidenciar as potencialidades de se estudar, visitar, conhecer e divulgar estes museus enquanto espaços não formais de educação.

\section{O Estágio Curricular Supervisionado nos cursos de licencia- tura da UFTM}

A UFTM oferece oito cursos de licenciatura, sendo dois deles ofertados em campus fora de sede, na cidade de Iturama/MG: Ciências Biológicas (campus Uberaba e campus Iturama), Física, Química (campus Uberaba e campus Iturama), Matemática, Geografia, História, Letras Português-Inglês/Letras Português-Espanhol e Licenciatura 
em Educação do Campo: áreas do conhecimento Ciências da Natureza ou Matemática. As informações que seguem foram extraídas dos Projetos Pedagógicos dos Cursos (PPC) supracitados no momento de sistematização deste texto (2018) e buscam elucidar as menções de educação não formal no currículo de formação dos futuros professores. Destaca-se, no entanto, que os cursos têm passado por atualizações em seus PPC, de modo a atender às novas diretrizes nacionais para a formação de professores.

O curso de Licenciatura em Ciências Biológicas, campus Uberaba, aborda as questões dos espaços não formais na disciplina de Estágio Curricular Supervisionado I, no quinto semestre do curso. Essa disciplina abrange a educação em espaços não formais (contextos não escolares); a mediação nos museus e em outros espaços culturais; a articulação entre Biologia e Cultura, percorrendo a cidade, mapeando espaços; discussão das articulações, contatos, aproximações possíveis entre ciências e arte; entre outros (UFTM, 2011a).

Por outro lado, o curso ofertado no campus de Iturama apresenta uma disciplina específica que trabalha com estes espaços: trata-se de "Espaços Não Formais de Educação e Divulgação da Ciência”, componente obrigatório ofertada no quinto semestre do curso, com carga horária de 60 horas. No $5^{\circ}$ semestre deste curso consta Estágio Curricular Supervisionado I, que abrange os espaços educativos escolares e não escolares; o ensino de Ciências e de Biologia em diferentes contextos educativos; o diálogo entre as pesquisas em Educação em Ciências e a prática de ensino de Ciências da Natureza e de Biologia (UFTM, 2015a).

Os cursos de Licenciatura em Física e de Licenciatura em Química do campus Uberaba, também abordam as questões dos espaços não formais na disciplina de Estágio Supervisionado I, desenvolvendo a caracterização dos processos educativos formais, não formais e informais; a relação Museu-Escola, os processos de ensino e de aprendizagem em espaços não formais de Educação; as perspectivas e tendências das pesquisas sobre a educação em espaços não formais; divulgação ci- 
entífica, popularização da ciência e da tecnologia e os espaços não for mais de educação e, ainda, cultura científica e as mostras de saberes. $\mathrm{O}$ Estágio I é obrigatório, ofertado no sexto período do curso (UFTM, 2010a, 2011d).

Na mesma perspectiva, o curso de Química ofertado no campus Iturama apresenta em seu PPC propostas que envolvem os espaços não formais no Estágio Supervisionado porém, na ementa da disciplina, não consta referência alguma a estes espaços. Além disso, o curso conta com uma disciplina de caráter optativo sobre o tema: "Espaços Não Formais de Educação e Divulgação da Ciência” (UFTM, 2015b).

O curso de Licenciatura em Matemática também trabalha os espaços não formais de educação no decorrer da disciplina Estágio Supervisionado I, no quinto semestre, de modo a reconhecer, analisar e refletir sobre o campo de estágio; caracterizar os processos educativos formais, não formais e informais; estabelecer a relação Museu-Escola; identificar os processos de ensino e aprendizagem em espaços não formais de educação e, também, as perspectivas e tendências das pesquisas sobre a educação em espaços não formais. Além disso, aborda a di vulgação científica em Matemática, a popularização da Matemática e da tecnologia e os espaços de educação não formais, bem como a cultura científica e mostras de saberes em matemática (UFTM, 2011c).

Sob outra perspectiva, o curso de Licenciatura em Geografia não faz menção específica aos espaços não formais de educação. $\mathrm{Na}$ ementa da disciplina de Estágio Supervisionado II, há referência às visitas que podem ocorrer a órgãos públicos vinculados aos sistemas de ensino e a espaços educativos diversificados, com o objetivo de ampliar a concepção de docência ao reconhecer o papel do educador em outros campos. Como exemplos destes espaços, há escolas que oferecem educação de jovens e adultos, espaços educativos que trabalham com adultos e terceira idade; espaços educativos tidos como pouco tradicionais; espaços educativos que trabalham com público com necessidades educativas especiais; museus, centros de Ciências, videotecas que 
desenvolvem visitas orientadas, ações educativas e processos formativos específicos para professores; parques, instituições e empresas que desenvolvem programas de educação ambiental; espaços que propiciam práticas de educação à distância (UFTM, 2014).

O curso de Licenciatura em História não trata de questões relativas aos espaços não formais em estágio supervisionado algum. Entretanto, o curso oferece uma disciplina eletiva sobre Patrimônio e Memória, desenvolvendo os conceitos de patrimônio cultural e patrimônio natural, sua relação com os conceitos de memória, de identidade e suas práticas na formação do historiador, na concepção de espaços museológicos, de centros de documentação e na educação patrimonial (UFTM, 2010b).

Ademais, os cursos de Licenciatura em Letras Português-Inglês e Português-Espanhol não abordam os espaços não formais de educação em seus respectivos estágios supervisionados, tampouco disciplinas optativas que trabalhem o tema (UFTM, 2010c, 2010d).

Por fim, o curso de Licenciatura em Educação do Campo: área de conhecimento Ciências da Natureza ou Matemática, apresenta em seu PPC uma descrição detalhada sobre Estágio Curricular Supervisionado I, oferecida no quinto semestre do curso, que aborda os espaços não formais de educação, de modo que os estagiários deverão organizar, juntamente com o professor orientador de estágio, um projeto de trabalho cuja finalidade seja conhecer de forma abrangente diferentes contextos educativos. Dessa forma, o objetivo desta etapa é conhecer cenários educativos diversificados, assim como personagens e tramas para o ensino, compreendendo museus e centros de ciências em que sejam desenvolvidas visitas orientadas, ações educativas e processos formativos específicos para professores (UFTM, 2011b).

Nota-se, portanto, que os estágios na UFTM, a partir de seus projetos pedagógicos, favorecem parcialmente a aproximação com os museus, uma vez que a carga horária destinada para esse tipo de espaço é reduzida e circunscrita, em geral, a apenas um dos quatro componentes de Estágio Curricular Supervisionado que cada curso apresenta. 
Atentemo-nos à importância dos museus como espaços de formação complementares à escola e à universidade, pois a integração do museu à escola/universidade representa, na maioria das vezes, um desafio para os futuros professores. Os efeitos de uma visita ao museu, com atividades de preparação e de posterior extensão em sala de aula, colocam-se como pertinentes para a reflexão e preparação de novos caminhos didáticos, aproximando a escola destes espaços. Ademais, estimulam os futuros professores a vivenciarem os museus em âmbito de sua formação inicial.

\section{Museu e a formação inicial de professores na UFTM}

Os museus configuram-se como ambientes que oferecem permanentes atividades com fins educativos e culturais que resultam em excelentes oportunidades de enriquecimento e aprendizagem. Marandino e colaboradores (2009) afirmam a importância de articulações com os espaços formais e apontam que, para compreender os ambientes educativos não formais como possibilidades de acesso da população à cultura científica, torna-se fundamental refletir e desempenhar ações educacionais desenvolvidas nesses outros espaços e tempos do ensino e da divulgação, em especial para o ensino de Ciências.

Nesse âmbito contempla-se o museu como espaço de aprendizagem, principalmente para a formação do professor. O Estágio Curricular Supervisionado em espaços não formais de educação tem como finalidade formar profissionais que reconhecem os museus como ambientes educativos, além de atuar nesses locais nas diferentes ações educativas que realizam (MARANDINO, 2003).

A realização dos estágios nas atividades de ensino e divulgação em museus possibilita aos licenciandos complementarem sua formação docente com um campo de atuação mais amplo, uma vez que os estágios nos cursos de licenciatura na UFTM apresentam carga horária destinada majoritariamente à observação de aulas em escolas, o que se coaduna à afirmação de Barzano (2008, p.3), para quem “[...] as emen- 
tas das disciplinas desta área, na maioria das universidades brasileiras, privilegiam a escola como espaço para que os licenciandos desenvolvam as atividades do estágio supervisionado”.

Com a possibilidade da mudança do lugar social do professor em formação, ou seja, da sala de aula de uma escola, para a divulgação em museus de ciências, o estágio pode ser realizado em uma atitude prospectiva. Nesse sentido, consideramos relevante pensar este componente curricular na perspectiva da aquisição de competências tanto em nível pessoal quando em nível intelectual, de modo a formar e qualificar o estagiário como profissional docente diferenciado, em vez de apenas estagiarem de maneira meramente "passiva" nas escolas.

Essa interação entre museu e estágio promove diferentes desafios ao estagiário, provocadores de reflexões e questões que levam o professor em formação a apresentar novas abordagens, por exemplo, acerca de como trabalhar a inclusão e a acessibilidade na instituição museológica. Segundo Marandino (2003), os conteúdos relacionados aos espaços não formais de educação na formação inicial permitem desenvolver os espectros de atuação competente do profissional de Educação em Ciências.

Apesar da relevância do assunto, são poucos os trabalhos que estudam a temática formação de professores e sua relação com museus e centros de ciência (NASCIMENTO et al., 2012). Ao pensar em formação de professores e seus enlaces com os espaços não formais, devese possibilitar a esses professores não apenas a formação referente à exposição em um determinado espaço, mas sim possibilitar que, após a formação, esses professores possam ter uma fundamentação teórica e prática a ser utilizada em qualquer outro espaço educativo não formal. Nesse contexto, considera-se que a atuação do professor representará sempre o diferencial do contato entre os alunos e as atividades ou experiências não formais, distinguindo o que é uma forma efetiva de aprendizado de uma mera visita recreativa.

Assim, o Estágio Curricular Supervisionado realizado nos espaços dos museus contribui de maneira profícua para o processo de 
formação de professores. Valendo-se da prática docente inicial, a atuação do estagiário no museu pode subsidiar as discussões sobre processos de ensino e aprendizagem nas instituições museais e, desta forma, contribuir com sua formação. Ademais, o estagiário se apropria dessa experiência para a prática em sala de aula, de modo a ampliar sua visão de mundo e buscar estabelecer conexões do conteúdo em outros ambientes que não sejam os escolares.

Conclui-se que ações mais diretas dos cursos de formação docente da UFTM junto aos museus se fazem necessárias de modo a buscar o fortalecimento dessas parcerias, além de possibilitar maior conhecimento sobre o contexto e permitir um enriquecimento formativo do próprio estagiário. Ressalta-se, ainda, a necessidade de maior investimento no processo de formação inicial de professores da instituição, para que estes se utilizem propriamente das especificidades pedagógicas das escolas e dos espaços não formais de educação.

\section{Referências}

ABCZ. Associação Brasileira dos Criadores de Zebu. Disponível em: $<\underline{\text { http:// }}$ www.zebu.org.br/Home/Secao/9530-Institucional.> Acesso em: 15 dez. 2018. ALLARD, M.; BOUCHER, S.; FOREST, L. e VADEBONCOEUR, G. Effets d"un programme éducatif muséal comprenant des activités de prolongement en classe. Revue canadienne de l' education, v. 20, n. 2, p. 166-180, 1995.

BARZANO, M. A. L. Educação não-formal: apontamentos ao Ensino de Biologia. Ciência em Tela. v. 1, n. 1, 2008.

BRANDÃO, C. R.; LANDIM, M. I. P. F. Museus: o que são e para que servem? In: SISEMSP. (Org.). Museus: o que são, para que servem? 1 ed., v. 02. São Paulo: ACAM-Portinari, 2011. p. 93-103.

BRASIL. Lei No 11.904, de 14 de janeiro de 2009. 2009. Disponível em: < http://www.planalto.gov.br/ccivil 03/ ato2007-2010/2009/lei/111904.htm.> Acesso em: 18 fev. 2019. 
CAZELLI, S. Jovens nos museus: quem são, aonde vão e com quem visitam? In: DALBEN, A.; DINIZ, J.; LEAL, L.; SANTOS, L. (Org.). Convergências e tensões no campo da formação e do trabalho docente. Belo Horizonte: $\mathrm{Au}$ têntica, 2010, p. 402-426. Disponível em: <https://perdigital.files.wordpress.com/2011/04/livro 5.pdf. $>$ Acesso em: 20 abr. 2017.

CCCP. Complexo Cultural e Científico de Peirópolis. UFTM, Uberaba. Dis-

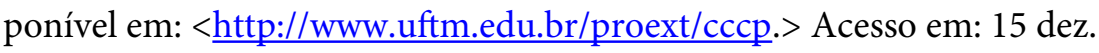
2018.

GAREAU, S. E.; GUO, R. X. Let's take an excursion! The use of museums in k-12 teacher education. In: ÉMOND, A. M. Le musée: entre la recherche et l'enseignement $=$ The Museum: between research and education. Québec: Éditions MultiMonds, 2012.

HOFSTEIN, A.; ROSENFELD, S. Bridging the Gap between Formal and Informal Science learning, 1996. Disponível em: <http://www.bobpearlman.org/BestPractices/Israel/Bridging\%20the\%20Gap.pdf.> Acesso em: 14 nov. 2018.

JACOBUCCI, D. F. C. Contribuições dos espaços não formais de educação para a formação da cultura científica. Em extensão, Uberlândia, v.7, 2008.

LAVOIE, S. Musée de la Nouvelle-France, prolégomènes à l'élaboration d'une politique de communication. Maîtrise en muséologie, Université du Québec à Montréal, Montréal, Québec, 1991.

MARANDINO, M. A formação inicial de professores e os museus de Ciências. In: SELLES, S. E.; FERREIRA, M. S. Formação docente em Ciências: memórias e práticas. Niterói: EdUFF. 2003. p. 59-76.

MARANDINO, M.; SELLES, S.E.; FERREIRA, M.S. Ensino de Biologia histórias e práticas em diferentes espaços educativos. São Paulo: Cortez, 2009.

MARANDINO, M. (Org.). Educação em museus: a mediação em foco. São Paulo: Grupo de Estudo e Pesquisa em Educação Não-formal e Divulgação em Ciências, 2008. Disponível em: < http://www.geenf.fe.usp.br/v2/wp-content/uploads/2012/10/MediacaoemFoco.pdf. Acesso em: 18 fev. 2019.>

NASCIMENTO, A. S.; et al. Estudo sobre a formação de professores em museus e centros de ciências: o espaço ciências interativa, um exemplo empíri- 
co. VI Jornada Interna de Iniciação Científica e Tecnológica, 2012, Rio de Janeiro. Resumos... Rio de Janeiro: Instituto Federal do Rio de Janeiro, 2012.

PUGLIESE, A. Os museus de ciências e os cursos de licenciatura em Ciências Biológicas: o papel desses espaços na formação inicial de professores. 2015. 231f. Tese (Doutorado em Educação) - Faculdade de Educação, Universidade de São Paulo, São Paulo, 2015.

QUEIROZ, Glória R. P. C. et al. Construindo saberes da mediação na educação em museus de ciências: o caso dos mediadores do Museu de Astronomia e Ciências Afins/Brasil. Revista Brasileira de Pesquisa em Educação em Ciências. v. 2, n. 2, p. 77-88, mai/ago.2002.

UBERABA. Prefeitura Municipal. Museus e Casa de Memórias. Disponível em: $<$ http://www.uberaba.mg.gov.br/portal/conteudo,619. Acesso em: $18 \mathrm{fev}$. 2019.>.

UFTM. Universidade Federal do Triângulo Mineiro. Projeto Político Pedagógico (PPC). Curso de Graduação em Física - Licenciatura, 2010a. Dispo-

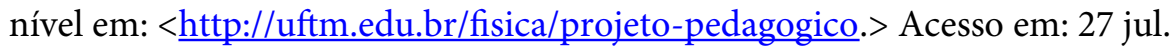
2018.

. Universidade Federal do Triângulo Mineiro. Projeto Político Pedagógico (PPC). Curso de Graduação em História - Licenciatura, 2010b. Disponível em: <http://uftm.edu.br/historia/projeto-pedagogico. $>$ Acesso em: 27 jul. 2018.

. Universidade Federal do Triângulo Mineiro. Projeto Político Pedagógico (PPC). Curso de Graduação em Letras Português-Espanhol - Licenciatura, 2010c. Disponível em: $<$ http://uftm.edu.br/letras-portugues-e-espanhol/projeto-pedagogico.> Acesso em: 27 jul. 2018.

. Universidade Federal do Triângulo Mineiro. Projeto Político Pedagógico (PPC). Curso de Graduação em Letras Português-Inglês - Licenciatura, 2010d. Disponível em: <http://uftm.edu.br/letras-portugues-e-ingles/ projeto-pedagogico.> Acesso em: 27 jul. 2018.

. Universidade Federal do Triângulo Mineiro. Projeto Político Pedagógico (PPC). Curso de Graduação em Ciências Biológicas - Licenciatura, 2011a. Disponível em: $<$ http://uftm.edu.br/ciencias-biologicas/projeto-pedagogico. $>$ Acesso em: 27 jul. 2018. 
. Universidade Federal do Triângulo Mineiro. Projeto Político Pedagógico (PPC). Curso de Graduação em Ciências Biológicas - Licenciatura, 2015a. Disponível em: $<$ http://uftm.edu.br/ciencias-biologicas-campus-iturama/projeto-pedagogico.> Acesso em: 27 jul. 2018.

. Universidade Federal do Triângulo Mineiro. Projeto Político Pedagógico (PPC). Curso de Graduação em Educação do Campo - Licenciatura, 2011b. Disponível em: $<$ http://uftm.edu.br/licenciatura-em-educacao-docampo/projeto-pedagogico.> Acesso em: 27 jul. 2018.

. Universidade Federal do Triângulo Mineiro. Projeto Político Pedagógico (PPC). Curso de Graduação em Matemática - Licenciatura, 2011c. Disponível em: $<\underline{\text { http://uftm.edu.br/matematica/projeto-pedagogico. }}>$ Acesso em: 27 jul. 2018.

. Universidade Federal do Triângulo Mineiro. Projeto Político Pedagógico (PPC). Curso de Graduação em Química - Licenciatura, 2011d. Dis-

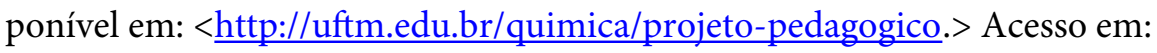
27 jul. 2018.

. Universidade Federal do Triângulo Mineiro. Projeto Político Pedagógico (PPC). Curso de Graduação em Química - Licenciatura, 2015. Disponível em: $<$ http://uftm.edu.br/quimica-campus-iturama/projeto-pedagogico. $>$ Acesso em: 27 jul. 2018.

. Universidade Federal do Triângulo Mineiro. Projeto Político Pedagógico (PPC). Curso de Graduação em Geografia - Licenciatura, 2014. Disponível em: < http://uftm.edu.br/geografia/projeto-pedagogico. $>$ Acesso em: 27 jul. 2018. 
